\title{
Family Environment, Emotional Regulation and Job Stress among Loco Pilots of Indian Railway
}

\author{
${ }^{1}$ Dr. Molly Joy, ${ }^{2}$ Ms. Akhila R Krishna \\ ${ }^{1}$ Professor and Head, ${ }^{2}$ I year M.Sc .Psychology, Department of Psychology, Kristu Jayanti College \\ ,Bangalore, India. 1dr.molly@kristujayanti.com, 11dr.mjoy14@gmail.com, \\ 2akhilarajkutty@gmail.com
}

\begin{abstract}
Loco pilots are one of the most significant posts in the railroad staff. The activity of Loco pilots in Indian Railway requests diligent work and incredible common sense alongside fearlessness to deal with various conditions. This study examines the Family Environment, Job Stress and Emotional Regulation among Loco pilots of Indian Railway. For the present study 70 Loco pilots were taken from different parts of the country through Exponential Non discriminative Snowball Sampling. The study findings indicated that there is a significant relationship between Family Environment, Job Stress and Emotional Regulation. The prediction model was statistically significant between Family Environment, Emotional Regulation and Job Stress.
\end{abstract}

Keywords: Emotional Regulation, Family Environment, Job Stress, Loco Pilots.

\section{INTRODUCTION}

Indian Railways is one of the biggest transportation and coordination systems of the world and runs in excess of 12,000 traveler conveying trains continuing 23 million travelers for each day and in excess of 7,000 cargo trains for each day persisting 3 million tons of cargo consistently over a system of 65,000 course kilometers. ${ }^{1}$ Its traffic thickness is third biggest on the planet and its wellbeing record regarding mishaps per million train kilometers is around 0.20 and fatalities per billion Passenger km 0.147, both well practically identical with that of cutting edge European Railways frameworks. ${ }^{2}$ Proficiency in nonstop activity of such an enormous volume of traffic securely in a multifaceted arrangement of Railways relies to a great extent upon the effectiveness of train activity staff liable for running these trains (Government of India, 2015). Indian Railways is taken to be the transport of national improvement. Traffic volume and speed in railroads will be expanded progressively with the progression of time and it should make worry in staff associated with train tasks. Loco pilots are one among these staffs. Karsek and Theorel (1990) $)^{\frac{3}{2}}$ have evaluated the occupations into four classifications: dynamic employments, low-strain occupations, uninvolved occupations and high-strain occupations. The employments of railroad motor pilots by all appearances go under the high-strain occupations as they need to perform extended periods of obligation and need to follow inflexible techniques and are permitted little scope for taking servers or time for individual needs. Report of Research Designs and Standard Organization (RDSO) 1997, uncovered a more elevated level of worry in railroad driver's activity in contrast with other occupation classes like train analysts and office agents.

At present Loco Pilots are ordered under 'nonstop' roaster without a scheduled rest time. Ordinarily the Loco Pilot needs to labor for 10 hours obligation at a stretch and can request help following 12 hours with 2 hours earlier notice to the controller (FIRE Quartly Magazine, Aug.2012). ${ }^{4}$ There are no fixed plans during working Goods trains. It typically takes long obligation hours (at times proceeds within 10 hours or more). While working Goods train, long hanging tight time for restoring his very own H.Q./Home Station (It is once in a while 30 hours or more). Loco-Pilot must be hung tight for the train at the hour of coming back to his H.Q./Home Station. Following 96 hours of Sign-Off Loco-Pilot request the mandatory returning for his H.Q. with a driving train or without a driving train. There are no quick returning calendars of loco-pilot. In any close to home or family crisis loco-pilot can't leave the taxi without Sign-Off. In any crisis loco-pilot called for obligation whenever he is in rest periods. The substantial clamor, dust contamination, abundance heat, high voltage power in the electric train and diesel smell in the diesel train are adding to early weakness to the group. The clamor level in a diesel train is about in excess of 100 decibels $^{5}$ which is 25 decibels more than most extreme permitted point of confinement of 75 decibels by the Industrial Pollution Control Board. The warmth, diesel smell, commotion from the motor room goes to the driving taxi as the entryways in the driving taxi are not planned for sound verification. To conquer this issue the train taxi must be cooled with the goal that weariness will not assault the drivers and they can focus on their obligations appropriately and guarantee 
security of trains. These factors causes physical tiredness as well as psychological disturbances like stress as well.The intro-psychic sector are important sectors of the life in which stress originates(Pestonjee, 1992) ${ }^{6}$.The causes and outcomes of stress are connected in complex manners. Hans Selye $(1975)^{\underline{7}}$ says that stressors are added substance. Basic results of pressure incorporate individual and authoritative outcomes just as burnout. Singular results are passionate responses, intellectual responses, mental and physiological introductions. Authoritative outcomes present as decrease in execution, withdrawal (non-appearance and stopping) and turnover, diminished inspiration and fulfillment. May be the greatest and limitless expenses of work related pressure are human causalities because of blunders made by laborers. It is basic for the Indian Railways to create pressure on the board methodologies that can furnish the human asset with successful adapting styles. For creating successful pressure on the executive systems, it seemed attractive to examine work related worry among railroad motor pilots, as they are legitimately identified with train

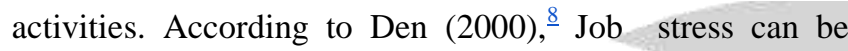
defined as "the harmful physical and emotional responses that occur when the requirements of the job do not match the capabilities, resources, or needs of the worker (Fernando et al., 2013). Those that are intrinsic to the job include long work hours, work overload, time pressure, difficult, demanding or complex tasks, lack of breaks, and poor physical work conditions (limited space, inconvenient temperature, limited or inappropriate lighting conditions) are causes of stress (Bakker et al., 2013).Railway employers go through a number of stressors when compared to other occupations (Pandey \& Srivastava, 2000). Job stress correlated significantly with fatigue, ergonomics of workplace, management pressure, high job demand, low control and low support at work, biological functions, and absenteeism (Prakash, Khapre, Laha \& Saran, 2010). When driving monotonous stretches at high speeds, the drivers' heart rate variability decreases, something that is considered to be a sign of increased mental workload and stress. (Myrtek Et al., 1994). However, according Heitmann et al., 1997), while drivers have very strenuous (irregular and long) work, with regular micro-sleep events during the night.

The Job stress a person is going through is essentially reflected in his/her Family Environment. A family and home condition has a solid effect on the general prosperity of a person. The family is by a wide margin the most significant essential gathering in the public eye. Truly, it has been changed from a pretty much independent unit into an unmistakable and constrained association of least size, comprising fundamentally of the first contracting equalities. The family is the most significant essential gathering in the public eye. It is the easiest and the most rudimentary type of society. It is the premise of every single social gathering. It is the first and the promptest social condition to which a kid is uncovered. The family, as an organization, is general. It is the most perpetual and the most inescapable of every single social foundation. All social orders huge and little, crude and socialized, antiquated and current have some type of family or the other. The conditions in a family particularly influence the job and working of a person. A feeling of having a place is gotten from the solid obligation of family. Families shape character, create character, enthusiastic quality, and work as an emotionally supportive network. People are not simply formed inside this sociological unit, which readies a person for routine experience yet in addition decides how he/she will respond to upsetting encounters.

The Job stress in a person triggers the emotional responses in an individual. Emotions bring about reaction to inside or outside upgrades that are significant to the person's survival or prosperity (John \& Gross, 2007) ${ }^{9}$. Emotions which show in explicit subjective, conduct, and physiologic reactions are conclusive for adjustment to new circumstances (Denollet, Nyklicek \& Vingerhoets, 2008), and are fundamental components for social cooperation in regular day to day existence. For instance, the correspondence of dread manages significant data of natural risks to the perceiver and shields the living beings from a wide assortment of dangers in spite of the protective reaction prompts nervousness issue which will prompt supported negative emotion, stress and evasion(Demirtas et al.,2015)Subsequently, emotion and its guideline assume a noteworthy job in regular social collaboration, relationship quality, critical thinking capacity and physical wellbeing (Adolph, 2010; Repetti, Tylor \& Seeman, 2002).Therefore, studying emotional regulation is also important. Thompson (1994) defined "emotion regulation as the process of initiating, maintaining, and modulating the occurrence, intensity, or duration of internal emotion states and the physiological processes related to emotions". Gross (2001) describes a process model of emotion regulation using the following definition: "Emotion regulation includes all of the conscious and unconscious strategies we use to increase, maintain, or decrease one or more components fact that being considered as a negative reaction, the dysregulation of this of an emotional response".

The performance of the train drivers decides the safety of the train movement failing which the train driver plunges him and the passengers /goods into serious mishaps which may involve economic loss to the organization.Therefore it is important to have a study on the Locopilots working in Railway.There are limited studies in the population which may be because of the difficulty in obtaining a good sample size. The 72 hours' continuous schedule and a less time break for relaxation makes it difficult for them to balance the Job stress, family and emotional regulation. These are less researched areas among Loco Pilots but it is important that we study these variables because these are the variables that are closely tied to the individual. The objective of the 
researcher is to find the Family Environment, Job Stress and Emotional Regulation among Loco pilots of Indian Railway.

\section{METHOD}

Correlation research design is used to find the relationship between Family Environment, Emotional Regulation, and Job stress among Loco Pilots of Indian Railway .Also to predict the role of family environment, Emotional Regulation contributes to Job stress among the Loco pilots. A correlation study is a type of research design where a researcher seeks to understand what kind of relationships variables have with one another. . $^{1 .}$

\section{VARIABLES OF THE STUDY}

Family Environment: Family Environment refers to the quality and quantity of the cognitive, emotional and social support that has been available to the person with in the family and connotes the scope psychological environment of family as perceived by individuals.

Emotional Regulation: Emotional Regulation is an emotion management process in which emotional activation and modulation abilities and strategies are used.

Job stress: Job stress, for the purposes of this study, will be theoretically defined as one's internal state or feelings of unpleasant emotions or reactions resulting from perceived undesirable work conditions that pose a threat to the individual (Jamal, 2007; Kahn \&Byosiere, 1990; Parker \&DeCotiis, 1983; Xie\& Johns, 1995). Job stress will be operationally defined as the subject's total score on the Job Stress Scale (Parker \&DeCotiis, 1983

Loco Pilot: It is a short form of the word Locomotive Pilot, which is a designation of an employee who is given the job of operating a train for its complete Journey or part of it.

OBJECTIVES OF THE STUDY: The following objectives guided the study:

1. To study the extent of prevalence of Family Environment, Job Stress and Emotional Regulation among Loco pilots.

2. To study the relationship among Family Environment, Job Stress and Emotional Regulation of Loco Pilots.

3. To predict the influence of Family Environment, Emotional Regulation on Job Stress among Loco pilots.

Null hypothesis was formulated to evaluate the objectives 2 and 3

\section{SAMPLING PROCEDURE OF THE STUDY}

The Universe of the sample consisted of the Loco pilots of Indian Railway. In order to arrive at a sample of 70 , the researcher used an Exponential non-discriminative snowball sampling method (Kirchherr, Julian \& Charles, Katrina, 2018). Researchers use this sampling method if the sample for the study is very rare or is limited to a very small subgroup of the population. This type of sampling technique works like chain referral. After observing the initial participant, the researcher asks for assistance from the subject to help identify people with a similar trait of interest. ${ }^{11}$ This kind of a sampling method was selected by the researcher as it is difficult to arrive at a good sample size. Communication with loco pilots and convincing them to collect data was quite difficult therefore consent form had to be explained to them then the scale was distributed among the 70 samples through Google Forms in and around the Northern and Southern parts of the country.

\section{TOOLS USED FOR THE STUDY}

Brief Family Relationship Scale (BFRS): Family Environment was measured using Brief Family Relationship Scale (BFRS). The BFRS is adapted from the 27-item Relationship dimension of the FES consisting 18 questions.High scores indicated higher Family cohesion and adjustment. The validity and reliability of the scale is in acceptable range on Indian samples. Internal consistency ranges from .61 to .78 for the ten subscales and the testretest reliability range from .68 to .86 . The coefficient of internal consistency, estimated by Cronbach's alpha was determined to be .75 and the validity of the scale is also high.

Job stress Scale: Job stress was measured using the Job Stress Scale (Parker \&DeCotiis, 1983). It is a 13-item summative Likert-type rating scale that measures overall job stress using anchors that range from 1 (strongly disagree) to 5 (strongly agree). The scale scores can range from 13-65 with higher scores indicating higher levels of job stress. The scale has a Cronbach's Alpha of 0.86.

Emotion Regulation Scale: This instrument was developed by Gross and John (2003), of self-report and fast application, consisting of 10 items. High scores indicated higher Emotional Regulation. The scale has a Cronbach's alpha of 0.73 .

\section{RESEARCH ETHICS FOLLOWED}

- Respondents consent had been sought through the consent form attached in Google Form.

- To do away with the ambiguity regarding the purpose of the research the aim and objectives of the research was explained in detail to each of the participants through telephonic conversation.

- Privacy was maintained among the respondents while asking questions 


\section{RESULTS}

Table 1: showing the descriptive statistics among variables.

\begin{tabular}{llll}
\hline Variables & $\mathrm{N}$ & Mean & SD \\
\hline Family Environment & 70 & 57.00 & 7.01 \\
Job stress & 70 & 57.51 & 9.52 \\
Emotional Regulation & 70 & 43.88 & 10.03
\end{tabular}

Table 1 shows that the Mean and Standard deviation for Family Environment, Job stress and Emotional regulation. The mean of the Family Environment is 57.00 and 7.01 respectively. The mean value of participants indicated that they receive an average support from the family when compared with the norms of the tool. The mean and standard deviation for the Job stress is 57.51 and 9.526 respectively. The mean value of participants indicates that they have high Job stress. The mean and standard deviation for Emotional Regulation is 43.88 and 10.032. The mean value of participants indicates that they have low Emotional Regulation which means that the ability to manage and cope up with emotions is not good. The scores indicate that they are good at dealing with their family relationship but not good at dealing with their own emotions. This may be because of the High job stress and the demands of the job.

Table 2: Inter correlation among Variables

\begin{tabular}{llll}
\hline Variables & $\mathbf{1}$ & $\mathbf{2}$ & $\mathbf{3}$ \\
\hline Family & 1 & $0.74^{* *}$ & $0.21^{*}$ \\
$\quad$ Environment & & & \\
Job Stress & & 1 & $-0.64^{* *}$ \\
Emotional & & & 1 \\
Regulation & & &
\end{tabular}

$* p<.05 * * p<.01$

Table 2 shows the inter correlation among variables Family Environment, Emotional Regulation and Job Stress. There is a significant relationship between Family Environment and Job Stress $(r=0.74, p<0.05)$. The results are found to be statistically significant and the null hypothesis was rejected. This is in agreement with the research conducted by Yogita,Shrikant and Kulage. $\frac{12}{2}$ There is a significant relationship between Family Environment and Emotional Regulation $(r=0.21, p<0.05)$. The results are found to be statistically significant and the null hypothesis was rejected. There is a significant relationship between Job stress and Emotional Regulation ( $r=-0.64, p<0.05)$. It was found to be negatively correlated.This is in agreement with the past research conducted by Scheibe, Susanne \& Zacher, and Hannes. ${ }^{13}$ The results are found to be statistically significant and the null hypothesis was rejected.
Table 3: Regression table showing Family Environment, Emotional Regulation as independent variable and Job Stress as independent variable.

\begin{tabular}{llllll}
\hline Source & $\mathrm{B}$ & $\mathrm{SE}$ & $\beta$ & $\mathrm{t}$ & $\mathrm{p}$ \\
\hline $\begin{array}{l}\text { Family } \\
\text { Environment }\end{array}$ & 1.030 & 0.989 & 1.041 & 1.337 & $* 0.037$ \\
$\begin{array}{l}\text { Emotional } \\
\text { Regulation }\end{array}$ & 1.075 & 1.129 & 2.071 & 1.585 & $* 0.040$ \\
\hline
\end{tabular}

$\mathrm{R}^{2}$ family environment $0.20: \mathrm{R}^{2}$ emotional regulation $=0$. 36: $p=005^{*}$

A linear regression analysis was conducted to evaluate how well Family Environment and Emotional Regulation predict Job Stress among Loco pilots. The correlations of the variables are shown in the above table. It can be found that between Family Environment and Job stress $(B=1.030$, $p<0.01)$, Emotional Regulation and Job Stress $(B=1.075$, $p<0.05$ ), for every point rise in Job stress, Emotional Regulation Increased by 1.075 time. Therefore, it is found that all correlations are statistically significant. Between Family Environment F (1,68=0.113, p>0.01) and Job Stress the model was significant and accounted for approximately 20 percent of the variance on Job Stress. The prediction model was statistically significant between Emotional Regulation. F $(1,68=0.342, \mathrm{p}<0.05)$ and accounted for approximately 36 percent of the variance on Job Stress.

\section{FINDINGS}

- The mean values indicated that there is an average level of Family Environment, Low Emotional Regulation and High level of Job Stress among Loco pilots.

- There is a significant relationship between Family Environment, Emotional Regulation and Job Stress.

- The prediction model was statistically significant between Emotional Regulation and accounted for approximately thirty-six percent of the variance on Job Stress.

- The prediction model was statistically significant between Family Environment and accounted for approximately twenty percent of the variance on Job Stress.

\section{CONCLUSION}

The results of the study suggested that Loco pilots received an average amount of support from the family, Low Emotional Regulation and High Job Stress. There is a significant relationship between Family Environment, emotional regulation and Job Stress. The prediction model was statistically significant between Family environments, Emotional Regulation on job stress. Ffindings of this study indicated that family environment and emotional regulation are important variable on job stress among Loco Pilots. Appropriate training and intervention programmes could be 
provided periodically to loco pilots to regulate emotions and can raise awareness about work family issues by which job stress can be probably reduced.

\section{SUGGESTIONS FOR FURTHER STUDY}

Although this study was carefully conducted, there were some limitations. There was a possibility that a larger sample size may have yielded different or more significant results on Family Environment, Job Stress and Emotional Regulation among Loco pilots. The prediction model suggests that more variables can be added. Similar studies can be conducted for aviation pilots or people who do similar kind of jobs.

\section{REFERENCES}

[1] Aminabhavi VA, Kamble SV. A Study on Work Motivation and Stress Coping Behaviour of Technical Personnel at Railway Work Shop. Journal of Community Guidance and Research. 2004; 21(3):321329.

[2] Anderson, S. E., Coffey, B. S., and Byerly, R. T. (2002), "Formal Organizational Initiatives and Informal Workplace Practices: Links to Work-Life Conflict and Job- Related Outcomes", Journal of Management, Vol. 28(6), pp.787-810.

[3] Anne Pisarski, Sandra A. Lawrence, Philip Bohle and Christine Brook (2008), "Organizational Influences on the Work Life Conflict and Health of Shift Workers", Applied Ergonomics, Vol. 39, pp. 580-588,

[4] Aryee, S., Srinivas, E.S., and Tan, H.H. (2005), "Rhythms of life: Antecedents and Outcomes of WorkFamily Balance in Employed Parents", Journal of Applied Psychology, Vol. 90, pp. 132-146.Available at: Google (accessed 12/12/2019).

[5] Colligan, M.J. and Rosa, R.R. (1990), "Shift Work Effects on Social and Family life",

[6] Job Medicine:

[7] Dawson, D., McCulloch, K., and Baker, A. (2006), "Extended Working Hours in Australia: Counting the Costs", Retrieved from the World Wide Web: http://www.dir.qld.gov.au/pdf/ir/extendedhours.pdf

[8] Gross, J. J. (1998). Antecedent- and response-focused emotion regulation: Divergent consequences for experience, expression, and physiology. Journal of Personality andSocial Psychology, 74, 224-

[9] Joanna Hughes and Nikos Bozionelos (2007), "Worklife Balance as Source of Job Dissatisfaction and Withdrawal Attitudes: An Exploratory Study on the Views of Male Workers", Emerald Group Publishing Limited, Vol. 36, No. 1, pp. 145-154.

[10] Johansson U, Bernspang B (2003), "Life Satisfaction Related to Work Re-entry afterBrain Injury: A Longitudinal Study", Brain Injury, Vol. 17, pp. 9911002.
[11]Jones, F., Kinman, G., and Payne, N. (2006), "Work Stress and Health Behaviours: Awork-life Balance Issue. In

[12]Jorn Bakker, Leszek Holenderski, Rafal Kocielnik, Mykola Pechenizkiy, Natalia Sidorova. Stress @ Work: From Measuring Stress to its Understanding, Prediction and Handling with Personalized Coaching. EIT ICT Labs, Thematic Line Health \& Wellbeing, 2013. (Downloaded at: http://eit.ictlabs.eu),Journal of Vocational Behavior, Vol. 63, pp. 510-531.

[13] Karasek R, Theorell T. Healthy Work: Stress, Productivity, and the Reconstruction of Working Life. New York: Basic Books, 1990.

[14] Karatepe OM, Kilic H \& Isiksel B (2008), “An Examination of the Selected Antecedents and Outcomes of Work-Family Conflict and Family-Work Conflict in Frontline Service Jobs", Service Marketing Quarterly, Vol. 1-2.

[15] MacEwen, K. E. and Barling, J. (1994), "Daily Consequences of Work Interference with Family and Family Interference with Work", Work and Stress, Vol. 8, pp.244-254.

[16] Ostan I, Poljsak B, Axelsson EP. Job Stress Perception and Healthy Lifestyle in Railroad Workers. PrometTraffic and Transportation. 2011; 23(3):195-203. http://dx.doi.org/10. 7307/ptt.v23i3.123.

[17] Pandey S, Srivastava S. Coping with Work Stress in Career Oriented Females. Journal of Community Guidance and Research. 2000; 17(3):313-323

[18]Pestonjee DM. Stress and Coping-The Indian Experience. New Delhi: Sage Publication, 1992.

[19] Productivity, and Corporate Financial Performance",

[20] Progress and Problems in Australian Organizations", Working Paper 58/02, (November).

[21]Ulla Kinnunen (2008), "Family-Supportive Organization Perceptions, Multiple Dimensions of Work-family Conflict, and Employee Satisfaction: A Test of Model Across Five Samples", Journal of Vocational Behavior, Vol. 73, pp. 92-106.

[22] Vatan, S., Lester, D., \& Gunn, J. F. (2014).Emotion Dysregulation, Problem-Solving, and Hopelessness. Psychological Reports, 114(2), 647-651.

[23] Wedderburn, A.A.I. (1967), "Social factors in satisfaction with swiftly rotating shifts", Job Psychology. 